\title{
各種イネ菌核病菌によるイネ葉鞘における 病徵の比較と一般水田における発生状況
}

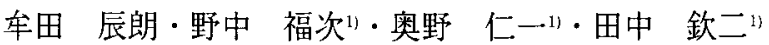 \\ （鹿児島県農業試験場大島支場・'佐賀大学農学部)
}

\begin{abstract}
Comparison of the symptoms on rice sheath caused by several sclerotial fungi and the occurrences of the disease in paddy fields. Taturo MUTA, Fukuji NONAKA', Jinichi OKUNO') and Kinji TANAKA (Oshima Branch, Kagoshima Agricultural Experiment Station, Naze, Kagoshima 894. 'Faculty of Agriculture, Saga University, Saga 840)

Recently, the occurrence of the so-called pseudo-sheath blight, similar to the lesions of rice sheath blight caused by Rhizoctonia solani ( $\mathrm{AG}^{-} 1$, sasakii type), is caus ing problems at harvesting time of rice plant. The lesions are mainly caused by the fol. lowing three fungi, culture type III B of Rhizoctonia solani (brwon sheath blight), Sclerotium oryzae-sativae (brown sclerotium disease) and Rhizoctonia oryzae (bordered sheath spot). The symptoms induced by artificial inoculation of these fungi were compared with the symptoms of sheath blight. Type III B of $R$. solani and S. oryzae-sativae were mainly isolated from pseudo-sheath blight lesions of rice plants collected from paddy fields at harvesting time.
\end{abstract}

イネ紋枯病は葉鞘に大型棈円の特徵ある病斑を形成す ることから，一般に最も病徴診断が容易な病害とされて いる。ところが出穂後イネが黄熟期になってくると，葉 䩗に紋枯病と類似した病斑を形成する，いわゅる疑似紋 枯病の発生が多くみられ，近年全国的に問題となってい る。このようなイネ紋枯病類似病斑を形成する病原菌は 紋枯病菌以外の菌核病菌であり, とくに, 褐色紋枯病菌 (Rhizoctonia solani，菌系融合型 AG 2-2 type，培養型 II B type)，赤色菌核病菌（Rhizoctonia oryzae）および褐色菌 核病菌 (Sclerotium oryzae-sativae) の 3 種が主体であるこ

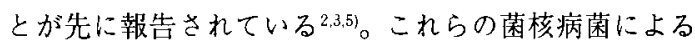
病斑は，先にも述べたように紋枯病（Rhizoctomia solani， 菌糸融合型 $\mathrm{AG}^{-1}$ type, 培養型 I A type）の病斑と類似 していることから，一般には紋枯病と見なされている場 合が多く，また，病徵でその病原菌を判定することは非 常に困難である。本実験は，水田栽培のイネにこれら4 種の菌核病菌を接種して発病させ，収穫期にこれらの菌 核病菌によって形成された病斑の病徵を比較検討してそ れらの特徴について述べると共に，佐賀県内一般水田か ら採集した紋枯病類似病斑から菌の分離を行い，各種菌 核病の発生状況を調查したものである。
試験 $1 ：$ 各種イネ菌核病菌によるイネにおける病徴の 比較

$$
\text { 材料と方法 }
$$

佐賀大学農学部構内水田に, 品種レイホウ(播種 5 月 25日）を6月28日，株間 $21 \times 22 \mathrm{~cm}, 1$ 株 4 本として移植， 栽培して実験に供試した。接種菌は紋枯病菌（390号 菌), 褐色紋枯病菌 (81-106号菌), 赤色菌核病菌 (81-141号菌), 褐色菌核病菌 (79-42号菌)を約70日間 いなわら培养した後，いなわらと共に 8 月 8 日と 8 月 25 日の 2 回, イネ株内の水際付近にはさみ込み接種した。 葉鞘に形成された病斑の調査は，10月下旬に刈り取っ て, 第 2 葉鞘と第 3 葉鞘の病斑について行った。調查荎 数と病斑数では, 紋枯病は 85 茎・ 367 病斑, 褐色紋枯病 は146茎・178病斑, 赤色菌核病は140茎・165病斑, 褐色 菌核病は40茎・134病斑について行った。まず，1葉鞘 当り病斑数を調へ，病徴別病斑数については, 第 1 図に 基づき，下記の通り $5 つ に$ 類別して，各病斑をそのいず れに属するかを数えて表示した。 


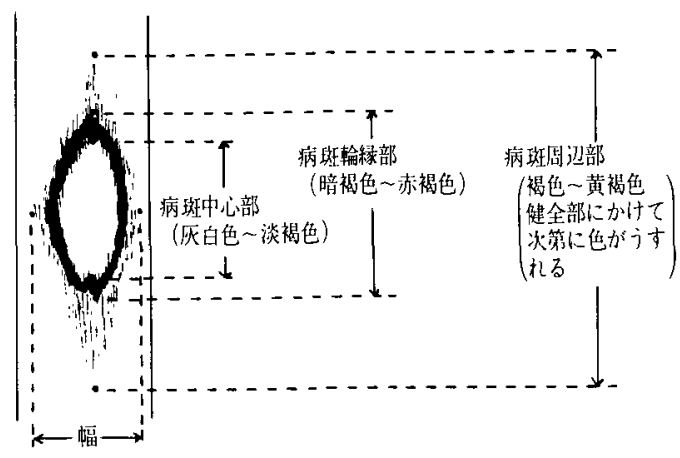

第 1 図紋枯病類似症の一般的病徵の模式図と病班各部

病 徵 別病 斑

\section{病斑型}

1 中心部は灰白色, 輪縁部は暗褐色, その外まわり の周辺部法淡褐色で, 紋枯病類似症(疑似紋枯病) の一般的病斑

2 輪縁部は不明暸または非常に細いが，中心部と周 辺部とは識別できる病斑（紋枯病の典型的病斑）

3 中心部が不明暸で, 全体が暗褐色の病斑

4 周辺部がなく, 中心部之輪縁部が明確な病斑

5 中心部, 輪縁部, 周辺部それぞれの区別が不明暸 で, 病斑全体が灰白色〜淡褐色を呈する病斑

(注) 病斑型 1 〜 は, いずれも紋枯病斑に類似し た病斑を形成するため，褐色，楕円の大型病斑を基 本にしており，第 1 図に示すように, 病斑各部を比 較した場合の病斑型である。

結

果

1. 1 葉鞘当りの病斑数と病徽別病斑形成率：第 1 表に示すように，1葉鞘当りの病斑数は紋枯病が最も多 く，ほとんどの病斑はゆ合して，大型病斑を形成する。 これに次いで多いのは褐色菌核病であり，小型の病斑を 多数形成し，ゆ合しているものも多くみられた。褐色紋 枯病と赤色菌核病はほぼ同数で, 1 葉鞘当り $1 \sim 3$ 個で
あった。病徵別病斑形成率では，1型は赤色菌核病で $87.9 \%$ と多く, 褐色紋枯病は $39.9 \%$, 褐色菌核病は 21. $6 \%$,紋枯病では非常に少なく $1.4 \%$ ですた。2 型は紋 枯病のほとんどがこの型で，ゆ合している個々の病斑 は, 灰色の細い縁どりがみられる。褐色菌核病では 46.

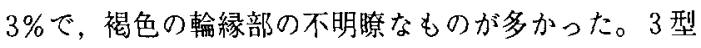
は紋枯病では全くみられず，他の 3 菌核病では，第 2 葉 鞘より第 3 葉鞘に多い傾向がみられた。4型は紋枯病で は全くみられず，赤色菌核病では $3 \%$ と少なく, 褐色菌 核病では $21.6 \%$ とやや多かった。 5 型は褐色紋枯病で最 も多くみられ，35.4\%であった。

2. 病斑長：病斑各部の平均長を第 2 図に示した。 ゆ合して大型病斑を形成する紋枯病斑は84mmであり，他 の 3 菌核病に比べて非常に長い。褐色紋枯病と赤色菌核 病は, ほとんどの病斑が単独に形成され，その長さはそ れぞれ $40 \mathrm{~mm}$ と $28 \mathrm{~mm}$ で，紋枯病斑長の $1 / 2$ と1/3であった。 褐色菌核病斑は，中合している病斑でも紋枯病斑のよう に大型とはならず，15mmであった。個々の病斑の輪縁部 と中心部の長さは，褐色紋枯病>紋枯病>赤色菌核病> 褐色菌核病であった。なお，暗褐色輪縁部の幅は，赤色 菌核病が他の菌核病よりやや広い傾向であった。輪縁部 の長さ別頻度分布を第 3 図に示した。紋枯病と赤色菌核 病では 6 - 25mmの病斑が多いが, 褐色紋枯病では大小の 病斑がみられ不均一であった。褐色菌核病は $10 \mathrm{~mm}$ 以下の 小病斑がほとんどであった。

3. 病斑の幅：結果を第 2 表に示した。紋枯病では 3/4 4/4（葉䩗全体を4/4とした）の病斑が多く，ほと んど茎をとり巻く大型病斑であった。これに対して，褐 色菌核病では $1 / 4$ 以下がほとんどであった。赤色菌核病 と褐色紋枯病では大小みられるが, 赤色菌核病では $1 / 4$ ー3/4が80.6\%であるのに対し，褐色紋枯病では3/4〜 4/4が30.5\%であり，幅の広い病斑も多かった。

4. 葉䩗上での病斑形成位置：結果を第 3 表に示し た(形成位置の区分は第 4 図に示した)。紋枯病と褐色 紋枯病では下位部に形成されることは少なく，中位から 上位部に多い傾向があった。特に第 3 葉鞘では, 褐色紋

第 1 表 病 徵 別 病 斑 数 $の$ 比較

\begin{tabular}{|c|c|c|c|c|c|c|}
\hline \multirow{2}{*}{ 病 } & \multirow{2}{*}{1 葉鞘当り病斑数 } & \multicolumn{5}{|c|}{ 病 徴 別 病 斑 形 成 率 } \\
\hline & & 1 & 2 & 3 & 4 & 5 \\
\hline 紋 枯 病 & $4.3(12)^{\mathrm{a}}$ & $1.4^{\%}$ & $97.6^{\%}$ & $0^{\%}$ & $0 \%$ & $0 \%$ \\
\hline 褐色紋枯病 & $1.2(3)$ & 39.9 & 4.5 & 9.0 & 11.2 & 35.4 \\
\hline 赤色菌核病 & $1.2(3)$ & 87.9 & 0 & 5.5 & 3.3 & 3.6 \\
\hline 褐色菌核病 & $3.4(9)$ & 21.6 & 46.3 & 9.0 & 21.6 & 1.5 \\
\hline
\end{tabular}

a（）は最多個数 


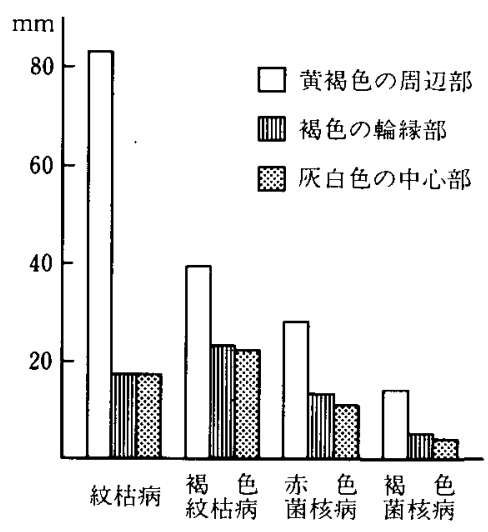

第2図各種菌核病の病斑長の比較

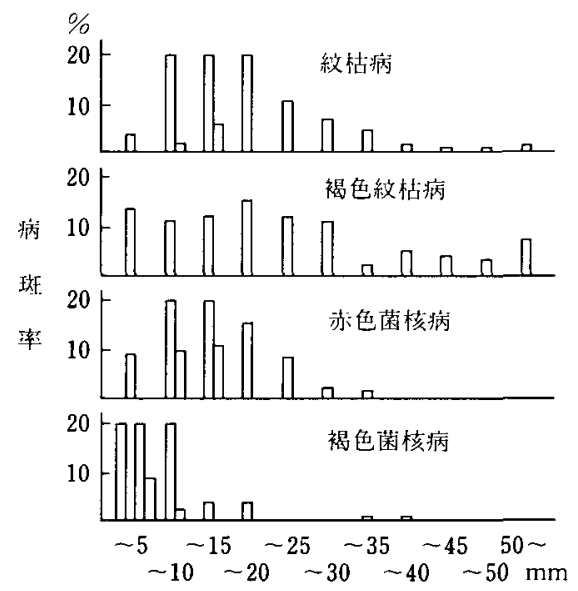

第3 図各病斑輪縁部の長さ別分布

第 2 表 各病斑 (周辺部) の幅別病斑率

\begin{tabular}{lcccc}
\hline 病 名 & $1 / 4$ 以下 & $1 / 4 \sim 2 / 4$ & $2 / 4 \sim 3 / 4$ & $3 / 4 \sim 4 / 4$ \\
\hline 紋 枯 病 & $1.1^{\%}$ & $6.6^{\%}$ & $8.8^{\%}$ & $83.5^{\%}$ \\
褐色紋枯病 & 19.5 & 34.5 & 15.5 & 30.5 \\
赤色菌核病 & 11.6 & 54.8 & 25.8 & 7.8 \\
褐色菌核病 & 89.1 & 6.5 & 3.3 & 1.1 \\
\hline
\end{tabular}

葉䩗全体をとり巻く病斑を $4 / 4$ とする

枯病斑の $63.6 \%$ が上位部に形成され，一方，赤色菌核病 と褐色菌核病では中位から下位部に多かった。

5. その他の病斑の特徵としては, 褐色級枯病では葉 䩗の縁に接して形成される病斑は，その縁に添って上下 へ流れるものが多くみられた。赤色菌核病斑の中心部は やや赤味を帯びるものがみられた。褐色菌核病斑は次葉 䩗に包まれた葉䩗にも病斑を形成するが，他の 3 菌核病 ではみられなかった。

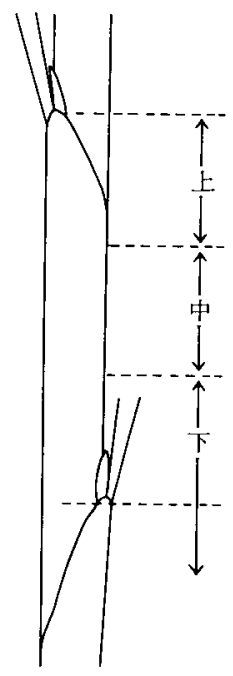

第 4 図葉鞘における病斑の形成部位

第 3 表 葉鞘上での形成位置別病斑率

\begin{tabular}{|c|c|c|c|c|}
\hline & 病 & 上. & 中 & 下 \\
\hline \multirow{4}{*}{ 第 2 葉䩗 } & 紋 枯 病 & $38.4^{\%}$ & $44.5^{\%}$ & $17.1^{\%}$ \\
\hline & 褐色紋枯病 & 29.3 & 50.7 & 20.0 \\
\hline & 赤色菌核病 & 4.8 & 57.7 & 37.5 \\
\hline & 褐色菌核病 & 0.6 & 37.2 & 62.2 \\
\hline \multirow{4}{*}{ 第 3 葉䩗 } & 皎 枯 病 & 38.5 & 38.5 & 23.0 \\
\hline & 褐色紋枯病 & 63.6 & 24.8 & 11.6 \\
\hline & 赤色菌核病 & 12.0 & 33.4 & 54.6 \\
\hline & 褐色菌核病 & 9.0 & 45.8 & 45.2 \\
\hline
\end{tabular}

試験 2 : 佐賀県内一般水田から採集した紋枯病類似病斑 から分離される菌核病菌

$$
\text { 材料と方 法 }
$$

1984年10月18日に，佐賀県内各地（第 4 表）の水田か ら紋枯病を除く紋枯病類似病斑を採集し, 病斑部を切り とり, 水洗後アルコール，アンチホルミンで表面殺菌 し, 素寒天培地で菌を分離し, PSA 培地上で菌核を形 成させ, 病原菌を同定した。

結

果

第 4 表に示したように，多く分離されたのは褐色紋枯 病菌と褐色菌核病菌で， $42.1 \%$ と $47.4 \%$ あっったが, 赤 色菌核病菌は 1 菌株であった。分離総茎数34茎のうち 4 茎からは, 褐色紋枯病菌と褐色菌核病菌の 2 種が分離さ れた。 
第 4 表 紋枯病類似病斑から分離される菌核病菌の 分離頻度

\begin{tabular}{|c|c|c|c|c|c|}
\hline 地 点 & 分離茎数 & 紋枯病菌 & $\begin{array}{c}\text { 䘽色 } \\
\text { 紋枯病菌 }\end{array}$ & $\begin{array}{c}\text { 赤色 } \\
\text { 菌核病菌 }\end{array}$ & $\begin{array}{c}\text { 褐色 } \\
\text { 菌核病菌 }\end{array}$ \\
\hline 小 城 & 2 & & 1 & & 1 \\
\hline 三 根 & 9 & & 6 & & 6 \\
\hline 三ケ月 & 2 & & 1 & & 1 \\
\hline 大 和 & 3 & & & 1 & 2 \\
\hline 千代田 & 1 & & & & 1 \\
\hline 金 立 & 17 & 3 & 8 & & 7 \\
\hline 合 計 & 34 & $\begin{array}{c}3 \\
(7.9)\end{array}$ & $\begin{array}{c}16 \\
(42.1)\end{array}$ & $(2.6)$ & $\begin{array}{c}18 \\
(47.4)\end{array}$ \\
\hline
\end{tabular}

（）は分離数に対する比率

\section{総}

括

以上の結果から，紋枯病拉よびその類似病斑を形成す る褐色紋枯病, 赤色菌核病, 褐色菌核病の病徵とその特 徵をまとめると次のようになる。

1. 紋枯病は，収穫期にはほとんど合した大型病斑 となり，個々の病斑の中心部は灰白色で，その外周に細 くて灰色〜灰褐色の輪縁部があり，これで周辺部抢よび 隣接病斑と区別できる。病斑のほとんどは，葉鞘全体を とり巻く形となっているものが多い。また，病斑は下位 葉鞘加上位葉䩗へと連続して形成される。

2. 褐色皎枯病の一般的病微は, 灰白色の中心部を暗 褐色の輪縁部が環状にとり巻き，さらに，その周囲に， 褐色一黄褐色で健全部にかけてしだいにその色が淡くな る周辺部をもつ病斑である。しかし，葉䩗の縁に接して 形成される病玟は上下へ流れるものが多い。また，中心 部や輪縁部が不明確な病斑も多い。病斑の大きさは，小 さいものから $50 \mathrm{~mm}$ を越す大型病斑もあり，赤色菌核病に 比へ不均一である。1 葉鞘に 1 ～2個の単独病斑を主に 葉䩗の上位部に形成する。

3. 赤色菌核病の病微は, 褐色紋枯病とよく類似して いるが, 中心部がやや赤味を带び, 輪縁部は褐色絞枯病 より幅が広く,やや明瞭なものが多い。病斑長は 5
$20 \mathrm{~mm}$ ，幅は葉䩗の $1 / 4 \sim 3 / 4 て ゙ ， 1$ 葉鞘に $1 ２$ 個の単独 病斑を，主に葉鞘下位部に形成する。

4. 褐色菌核病は, 紋枯病, 褐色紋枯病, 赤色菌核病 のいずれの病斑に比べても小さく, $10 \mathrm{~mm}$ 以下の病斑を, 葉䩗の下位部に数個形成し，中合する病斑が多い。しか し，紋枯病のような大型病斑とはならない。また輪縁部 が細く，不明瞭なものが多い。本病は下位葉鞘に包まれ た葉鞘にも病班を形成する。

本実験の結果は，鬼木1の記載とほぼ一致したが，病 斑長については前報3゙と異なる点もあった。本実験と は別に，一般水田から採集した紋枯病類似病斑について 菌の分離を行った結果でも，褐色紋枯病菌と褐色菌核病 菌が多く分離され，赤色菌核病菌もわずかに分離され た。これら 3 種菌核病のうち，とくに，褐色紋枯病と赤 色菌核病は，病徵で判定することは非常に困難であっ た。また，同一菱の病斑から 2 種の菌核病菌が分離され ることもあったことから，今後，本実験結果をもとに自 然発病での病徽別に菌の分離を行うと共に，菌核形成， 生育期別の病徴等について検討する必要がある。

\section{摘}

\section{要}

近年，収穫期のイネに，紋枯病によく類似した病玟を 形成する，いわゆる疑似紋枯病が多く発生して問題とな っている。この病斑は褐色紋枯病菌, 赤色菌核病菌抢よ び褐色菌核病菌によって形成される場合が多く，これら の菌の人工接種によって病斑を形成させ，その特徵を詳 細に検討した。また，一般水田から採集した疑似紋枯病 斑について菌の分離を行った結果, 褐色紋枯病菌と褐色 菌核病菌が多く分離された。

\section{引用 文 献}

1) 鬼木正臣（1979）植物防疫 $33(9) ： 1-7 。 2 ）$ 野中福 次. 田中欽二 - 坂田晃 (1979）九病虫研会報 $25: 3-5$. 3) 野中福次・吉田政博 - 田中欽二(1980) 九病虫研会報 26 ： 23-26. 4) 野中福次·吉田政博・游俊明・田中欽二（1982） 九病虫研会報 $28: 15-18$.5）野中福次・吉田政博・游俊 明・田中欽二 (1982) 九病虫研会報 $28: 18-21$.

(1985年 4 月25日 受領) 